\title{
Evaluating the potential of using urine and saliva specimens for malaria diagnosis in suspected patients in Ghana
}

\author{
Enoch Aninagyei ${ }^{{ }^{*}}\left(\mathbb{D}\right.$, Joseph Abraham², Paul Atiiga² ${ }^{2}$, Shadrach Duodu Antwi ${ }^{2}$, Stephen Bamfo ${ }^{2}$ \\ and Desmond Omane Acheampong ${ }^{2^{*}}$
}

\begin{abstract}
Background: This study aimed at detecting PfHRP2 and pLDH malaria antigens in urine and salivary specimens of suspected malaria patients using RDT kits, and identifying factors influencing the detection of these antigens.

Methods: Malaria rapid test kit (SD Bioline RDT kit) was used to detect malaria antigens, PfHRP2 and pLDH, in blood, urine and saliva samples received from patients suspected of malaria. Subsequently, malaria parasitaemia was determined. From the same patients, body temperature readings and haemoglobin concentrations were recorded. Also, micro-haematuria and saliva occult blood were determined. Relative to blood, the sensitivities and the performance of urine and saliva as alternative samples were evaluated.

Results: A total of 706 suspected malaria patients provided all three specimens. Prevalence of malaria by microscopy and RDT was $44.2 \%$ and $53.9 \%$, respectively. Compared to blood, the sensitivities of urine and saliva were $35.2 \%$ and $57.0 \%$ respectively. Haemoglobin concentration $<9.9 \mathrm{~g} / \mathrm{dL}$, body temperature $>38.7^{\circ} \mathrm{C}$ and occult blood influenced the detection of malaria antigens in both urine and saliva. Furthermore, the antigens were not detected in urine and saliva when parasitaemia was $<60,000$ parasites $/ \mu \mathrm{L}$ and $<40,000$ parasites $/ \mu \mathrm{L}$, respectively.

Conclusion: Saliva, with or without blood contamination, was found to be more efficient that urine samples. Therefore these non-blood specimens have the potential to be used as non-invasive samples for malaria diagnosis. However, this approach is useful in severe to moderate anaemia, hyperthermia, parasitaemia $>60,000$ parasites $/ \mu \mathrm{L}$ and samples contaminated with blood.
\end{abstract}

Keywords: Malaria antigens in urine, Malaria antigens in saliva, Ga west municipality, Ghana

\section{Background}

Malaria is one of the highest killer diseases predominant in sub-Saharan Africa (SSA). In 2018, about 212 million new infections and 381,000 deaths were reported in SSA [1]. In Ghana, Plasmodium falciparum account

\footnotetext{
*Correspondence: eaninagyei@uhas.edu.gh; dacheampong@ucc.edu.gh ${ }^{1}$ Department of Biomedical Sciences, School of Basic and Biomedical Sciences, University of Health and Allied Sciences, PMB 31, Ho, Volta Region, Ghana

${ }^{2}$ Department of Biomedical Sciences, School of Allied Health Sciences, University of Cape Coast, Cape Coast, Ghana
}

for $90-98 \%$ of all malaria cases [2]. The World Health Organization (WHO) recommends laboratory confirmation of all malaria cases before initiation of treatment [3]. Timely diagnosis and appropriate treatment are essential for addressing the global burden of malaria. Blood specimen is commonly used to perform malaria diagnosis using microscopes and rapid diagnostic test (RDTs) kits. Blood collection requires an invasive procedure using hypodermic needles [4].

Invasive phlebotomy can cause adverse effects, such as pain or bruising at the site of puncture, fainting, nerve damage and haematoma [5] in patients. Again, poor

(c) The Author(s) 2020. This article is licensed under a Creative Commons Attribution 4.0 International License, which permits use, sharing, adaptation, distribution and reproduction in any medium or format, as long as you give appropriate credit to the original author(s) and the source, provide a link to the Creative Commons licence, and indicate if changes were made. The images or other third party material in this article are included in the article's Creative Commons licence, unless indicated otherwise in a credit line to the material. If material is not included in the article's Creative Commons licence and your intended use is not permitted by statutory regulation or exceeds the permitted use, you will need to obtain permission directly from the copyright holder. To view a copy of this licence, visit http://creativeco mmons.org/licenses/by/4.0/. The Creative Commons Public Domain Dedication waiver (http://creativecommons.org/publicdomain/ zero/1.0/) applies to the data made available in this article, unless otherwise stated in a credit line to the data. 
infection-control practices can lead to microbial infections at the site where the needle was inserted into the skin [6] and for that matter, both patients and health workers can be exposed to blood borne infections from infected people [7-9].

Due to the potential demerits of invasive phlebotomy, diagnosis of diseases based on non-invasive procedures have been suggested and evaluated in some studies [10]. Urine and saliva are the two most popular alternatives to blood for diagnosis of diseases such as malaria [11]. Collection of urine and saliva do not require invasive procedures. It is simple, safe, painless and can be done by individuals with limited training, including patients themselves. No special equipment is also needed for collection, and it allows for multiple or serial collections outside of the hospital.

Previous studies in Ghana and in the Philippines detected PfHRP2 antigens in saliva of malaria patients using enzyme immuno-assays $[12,13]$. Using RDT kits, sensitivities of $\mathrm{pLDH}$ was found to be $77.9 \%$ in whole saliva and $48.4 \%$ in saliva supernatant [14]. In Papua New Guinea, the sensitivity of RDT kit in detecting PfHRP2 in urine samples from malaria patients was reported to be $81.0 \%$ [15].

Even though previous studies identified PfHRP2 and pLDH in salivary and urine samples, detection of these proteins were done mostly with sensitive diagnostic techniques (enzyme immuno-assays and fluorescent immuno-assays), which are only available in reference and specialized laboratories. Malaria is mostly endemic in rural and peri-urban areas where there is lack of technical expertise to perform complex analytical assays and cost involved in establishing these assays is always high. Therefore, this study was designed to detect PfHRP2 and $\mathrm{pLDH} P$. falciparum specific antigens in urine and salivary specimens from the same patients using readily available RDT kits and identify factors influencing the detection of these antigens in urine and saliva of $P$. falciparum infected individuals.

\section{Methods}

\section{Study sites and period of sample collection}

Blood, urine and saliva specimens were collected from clinically suspected malaria patients from Oduman Health Centre, Kotoku Health Centre, Mayera Health Centre and Pokuase Health Centre. These health centres are located in rural communities in the Ga West Municipality in the Greater Accra Region of Ghana. Samples were collected from October 2018 to May 2019.

\section{Included and excluded patients}

Clinically suspected malaria patients included in this study were at least 5 years old. Patients less than 5 years and those unable to provide urine and saliva were excluded from the study.

\section{Sample size determination}

Sample size was determined using the formula: $\mathrm{n}=\mathrm{z}^{2} \mathrm{p}(1-\mathrm{p}) / \mathrm{d}^{2}$, where $\mathrm{n}=$ sample size, $\mathrm{p}=$ prevalent of malaria in Ga West Municipality, $z=$ confidence level at 95\% (standard value of 1.96), $\mathrm{d}=$ margin of error at $5 \%$ (standard value of 0.05). The prevalence of malaria in $\mathrm{Ga}$ West Municipality was unknown so it was estimated at $50.0 \%$. Therefore, the minimum sample size was calculated to be 384 .

\section{Blood, urine and salivary samples collection}

Blood samples (approx. $4 \mathrm{~mL}$ ) were collected by venipuncture into $\mathrm{K}_{3}$ EDTA tubes (Micropoint Diagnostics, China), $30 \mathrm{~mL}$ of urine and saliva (approx. $5 \mathrm{~mL}$ ) were collected from the same patient. Due to difficulties in obtaining early morning urine, samples were collected between 6 a.m. and 10 a.m. Urine and salivary samples were frozen at $-20{ }^{\circ} \mathrm{C}$ till they were transported to $\mathrm{Ga}$ North Municipal Hospital Laboratory, Ofankor-Accra for analysis. However, whole blood was stored between 2 and $8{ }^{\circ} \mathrm{C}$ prior to analysis. Sample storage ranged between 15 and $48 \mathrm{~h}$.

\section{Laboratory analyses \\ Malaria microscopy}

Malaria parasites were quantified with the aid of Giemsa staining ( $\mathrm{pH}=6.8)$. Exactly, $6 \mu \mathrm{L}$ of whole blood was used to prepare thick smears measuring approx. $2 \mathrm{~cm}$ in diameter. Air dried thick films were stained with $10 \%$ Giemsa for $10 \mathrm{~min}$ and asexual stages of parasites estimated using the WHO protocol for malaria parasites estimation [16]. In brief, parasite densities were determined by dividing the number of parasites counter per at least 200 leukocytes and multiplied by estimated WBC count of 8000 cells $/ \mu \mathrm{L}$.

\section{Malaria rapid diagnostic testing using blood}

Malaria parasites antigenaemia (PfHRP2 and pLDH) were detected by SD Bioline rapid diagnostic test kit (Gyeonggi-do, Republic of Korea) following manufacturer's recommendation. In summary, $5 \mu \mathrm{L}$ of well-mixed whole blood was dispensed into the sample window of the kit followed by four drops of buffer. Test results were read at $15 \mathrm{~min}$.

\section{Malaria rapid diagnostic testing using saliva and urine}

PfHRP2 and pLDH antigens were detected in saliva and urine samples using SD Bioline rapid diagnostic test kit with some modifications. Optimized sample volumes were $20 \mu \mathrm{L}$ of saliva and $30 \mu \mathrm{L}$ of urine specimens. About 
$5 \mathrm{~s}$ after addition of samples into the sample window of the RDT kit, four drops of buffer were added. Test results were read at $15 \mathrm{~min}$.

\section{Determination of micro-haematuria and occult blood in saliva}

Blood in saliva and urine specimens were detected using the blood determinant portion of Uritest $10 \mathrm{E}$ urine reagent strip (Guangxi, China) following the manufacturer's procedure. Blood in the specimens were determined based on the pseudoperoxidase action of hemoglobin and erythrocytes which catalyzes the reaction $3,3^{\prime}, 5,5^{\prime}$-tetramethyl-benzidine and buffered organic peroxide. The blood determinant portion of the urine reagent strip was immersed in the sample (urine or saliva) for about $10 \mathrm{~s}$. Results were read at $45 \mathrm{~s}$. The resulting colors ranged from yellow-green to dark green depending on the amount of blood present in the sample. The test kit had sensitivity of 1 intact red blood cells/10 mL or $0.3-$ $0.6 \mathrm{mg} / \mathrm{L}$ of haemoglobin.

\section{Determination of haemoglobin concentrations}

Haemoglobin concentrations were determined using Urit 5200 (Guangzhou, China) fully automated haematology analyzer. Well-mixed whole blood was aspirated by the analyzer and haemoglobin concentrations were determined automatically using cyanide free colorimetric method. Haemoglobin concentrations in g/dL were generated within a minute.

\section{Data processing and statistical analysis}

Laboratory data were processed by Microsoft Excel 2016. The sensitivities, specificities, positive and negative predictive values were determined based on the following formula and their respective $95 \%$ confidence intervals as well as the Chi-square goodness of fit of each technique were determined by SPSS Version 24 (Chicago, IL, USA).

Sensitivity $=$ true positive $/($ true positive + false negative $) \times 100 \%$,

Specificity $=$ true negative $/($ true negative + false positive $) \times 100 \%$,

PPV $=$ true positive $/($ true positive + false positive $) \times 100 \%$,

$\mathrm{NPV}=$ true negative $/($ true negative + false negative $) \times 100 \%$,

where PPV and NPV are positive and negative predictive values respectively.

Accuracy was calculated based on the formula: Sensitivity $\times$ Prevalence + Specificity $\times(1-$ Prevalence $)$.

Table 1 Demographic characteristics of suspected malaria patients

\begin{tabular}{llllll}
\hline Demographic variables & Overall $(\mathbf{n}=\mathbf{7 0 6})$ & Kotoku $(\mathbf{n = 1 6 1 )}$ & Mayera $(\mathbf{n = 1 0 7 )}$ & Oduman $(\mathbf{n}=\mathbf{2 5 0})$ & Pokuase $(\mathbf{n}=\mathbf{1 8 8})$ \\
\hline Gender & & & & & \\
Females n (\%) & $405(57.3 \%)$ & $90(55.9 \%)$ & $71(66.3 \%)$ & $135(54.0 \%)$ & $108(57.4 \%)$ \\
Males n (\%) & $301(42.7 \%)$ & $71(44.1 \%)$ & $36(33.7 \%)$ & $115(46.0 \%)$ & $80(42.5 \%)$ \\
Age (years) & & & & \\
$1-10$ & $225(31.8 \%)$ & $50(31.0 \%)$ & $19(17.7 \%)$ & $102(40.8 \%)$ & $54(28.7 \%)$ \\
$11-20$ & $152(21.5 \%)$ & $36(22.3 \%)$ & $53(49.5 \%)$ & $43(17.2 \%)$ & $20(10.6 \%)$ \\
$21-30$ & $107(15.1 \%)$ & $17(10.5 \%)$ & $17(15.9 \%)$ & $20(8.0 \%)$ & $53(28.2 \%)$ \\
$31-40$ & $108(15.3 \%)$ & $27(16.7 \%)$ & $10(9.3 \%)$ & $41(16.4 \%)$ & $30(15.9 \%)$ \\
$41-50$ & $72(10.2 \%)$ & $9(5.6 \%)$ & $8(7.4 \%)$ & $31(12.4 \%)$ & $24(12.7 \%)$ \\
Above 50 & $42(5.9 \%)$ & $22(13.6 \%)$ & $0(0.0 \%)$ & $13(5.2 \%)$ & $7(3.7 \%)$
\end{tabular}

Kotoku Kotoku Health Centre, Mayera Mayera Health Centre, Oduman Oduman Health Centre, Pokuase Pokuase Health Centre 


\section{Results}

\section{Description of suspected malaria patients}

A total of 864 suspected malaria patients were recruited for this study. Of this number 706 (81.7\%) patients were able to provide all three samples (blood, urine and saliva) for analysis. Table 1 represents the demographic characteristics of suspected malaria patients that were able to provide all specimens. In all health facilities, more than $50 \%$ of the participants were females. The overall mean age (25th-75th percentile) of participants was 22.3 years (6-39 years). With the exception of participants recruited from Pokuase Health Centre, over 50\% of all participants from other sites were less than 21 years.

\section{Distribution of results by sample type and study sites}

The overall prevalence of $P$. falciparum parasitaemia in Ga West Municipality by microscopy was $44.2 \%$ (312/706) while PfHRP2/pLDH antigenaemia was 53.9\% (381/706). Highest malaria parasitaemia and antigenaemia was seen in Mayera Health Centre while relatively lower cases were seen in Pokuase Health Centre. Of the total malaria RDTs done on blood samples, 95\% (362/381) were PfHRP2 while 5.0\% (19/381) were both PfHRP2 and pLDH. Of the total of 706 urine samples tested, malaria antigens were detected in 134 samples (18.9\%). Of the 134 positive urine samples, both PfHRP2 and pLDH antigens were detected in 15 (11.2\%) samples contain malaria antigens. Both PfHRP2 and pLDH were detected in $92.2 \%(200 / 706)$ of saliva specimens while only PfHRP2 was detected in $7.8 \%(17 / 706)$ of saliva specimens. The distribution of the results in each study site is presented in Table 2.

\section{Clinical characteristics of blood RDT confirmed malaria patients}

In all, RDT detected PfHRP2/pLDH antigens in 132 (34.6\%) patients with haemoglobin concentration less than $9.9 \mathrm{~g} / \mathrm{dL}$ whilst in patients with haemoglobin concentration 10.0-12.5 g/dL and > $12.5 \mathrm{~g} / \mathrm{dL}$, PfHRP2/ pLDH antigens were detected in 170 (44.6\%) and 79 (20.7\%) blood specimens. Over half of the salivary specimens were found to contain occult blood (52.2\%), while only $29.4 \%$ of the urine samples were micro-haematuric. The overall mean temperature of the patients was $38.6 \pm 0.72{ }^{\circ} \mathrm{C}$. The distribution of the clinical findings among the four study sites are presented in Table 3.

\section{Sensitivities and specificities of urine and salivary specimens for detecting malaria antigens}

Table 4 represents the diagnostic performance of urine and salivary specimens for diagnosing malaria. Compared to blood specimen, urine specimen was $35.2 \%$

Table 2 Sample related prevalence of Plasmodium falciparum antigens in the study sites

\begin{tabular}{|c|c|c|c|c|c|c|}
\hline \multirow[t]{2}{*}{ Sample type } & \multirow[t]{2}{*}{ Positive n (\%) } & \multirow[t]{2}{*}{ Negative n (\%) } & \multicolumn{4}{|l|}{ Positive samples } \\
\hline & & & $\begin{array}{l}\text { Kotoku } \\
(n=161) n(\%)\end{array}$ & $\begin{array}{l}\text { Mayera } \\
(n=107) n(\%)\end{array}$ & $\begin{array}{l}\text { Oduman } \\
(n=250) n(\%)\end{array}$ & $\begin{array}{l}\text { Pokuase } \\
(n=188) n \\
(\%)\end{array}$ \\
\hline Microscopy & $312(44.2)$ & $394(55.8)$ & $69(42.8)$ & $67(62.6)$ & $103(41.2)$ & $73(38.8)$ \\
\hline \multicolumn{7}{|l|}{ Rapid diagnostic test (blood) } \\
\hline Total PfHRP2/pLDH detected & $381(53.9)$ & $325(46.0)$ & $94(58.4)$ & $71(66.4)$ & $127(50.8)$ & $89(47.3)$ \\
\hline Only PfHRP2 detected & $362[95.0]^{\mathrm{a}}$ & & $89[94.7]^{a}$ & $67[94.3]^{\mathrm{a}}$ & $120[94.4]^{\mathrm{a}}$ & $86[96.6]^{a}$ \\
\hline Both PfHRP2/pLDH detected & $19[5.0]^{a}$ & & $5[5.3]^{\mathrm{a}}$ & $4[5.6]^{\mathrm{a}}$ & $7[5.5]^{\mathrm{a}}$ & $3[3.7]^{\mathrm{a}}$ \\
\hline \multicolumn{7}{|l|}{ Rapid diagnostic test (urine) } \\
\hline Total PfHRP2/pLDH detected & $134(18.9)$ & $572(81.1)$ & $27(16.7)$ & $31(29.0)$ & $39(15.6)$ & $37(19.7)$ \\
\hline Only PfHRP2 detected & $119[88.8]^{\mathrm{a}}$ & & $27[100.0]^{\mathrm{a}}$ & $27[87.1]^{\mathrm{a}}$ & $32[82.0]^{\mathrm{a}}$ & $33[89.2]^{\mathrm{a}}$ \\
\hline Both PfHRP2/pLDH detected & $15[11.2]^{\mathrm{a}}$ & & $0[0.0]^{\mathrm{a}}$ & $4[12.9]^{a}$ & $7[18.0]^{\mathrm{a}}$ & $4[10.8]^{a}$ \\
\hline \multicolumn{7}{|l|}{ Rapid diagnostic test (saliva) } \\
\hline Total PfHRP2/pLDH detected & $217(30.7)$ & 489 (69.3) & $49(30.4)$ & $57(53.3)$ & $68(27.2)$ & $43(22.9)$ \\
\hline Only PfHRP2 detected & $200[92.2]^{a}$ & & $45[91.8]^{\mathrm{a}}$ & $53[92.9]^{a}$ & $63[92.6]^{a}$ & $39[90.7]^{a}$ \\
\hline Both PfHRP2/pLDH detected & $17[7.8]^{\mathrm{a}}$ & & $4[8.1]^{\mathrm{a}}$ & $4[7.0]^{\mathrm{a}}$ & $5[7.3]^{\mathrm{a}}$ & $4[9.3]^{\mathrm{a}}$ \\
\hline
\end{tabular}

Kotoku Kotoku Health Centre, Mayera Mayera Health Centre, Oduman Oduman Health Centre, Pokuase Pokuase Health Centre

a Percentages-proportion of total RDT positives that were either PfHRP2 or pLDH positive

while the rest contained only PfHRP2 antigens. In saliva samples, 217 out of 706 samples (30.7\%) were found to 
Table 3 Clinical findings of patients with malaria parasites antigenaemia

\begin{tabular}{|c|c|c|c|c|c|}
\hline Clinical parameters & Overall $(n=381)$ & Kotoku $(n=94)$ & Mayera $(n=71)$ & Oduman $(n=127)$ & Pokuase $(n=89)$ \\
\hline \multicolumn{6}{|c|}{ Haemoglobin concentration } \\
\hline$<9.9$ g/dL n (\%) & $132(34.6)$ & $33(35.1)$ & $29(40.8)$ & 49 (38.5) & $21(23.6)$ \\
\hline $10.0-12.5 \mathrm{~g} / \mathrm{dL} \mathrm{n}(\%)$ & $170(44.6)$ & $43(45.7)$ & $31(43.6)$ & $57(44.8)$ & $39(43.8)$ \\
\hline$>12.5$ g/dL n (\%) & $79(20.7)$ & $18(19.1)$ & $11(15.4)$ & $21(16.5)$ & $29(32.6)$ \\
\hline \multicolumn{6}{|l|}{ Occult blood in saliva } \\
\hline Present n (\%) & $199(52.2)$ & $42(44.7)$ & $52(73.2)$ & $59(46.4)$ & $46(51.6)$ \\
\hline Absent n (\%) & $182(47.8)$ & $52(55.3)$ & $19(26.8)$ & $68(53.5)$ & $43(48.3)$ \\
\hline \multicolumn{6}{|l|}{ Micro-haematuria } \\
\hline Present n (\%) & $112(29.4)$ & $29(30.8)$ & $27(38.0)$ & $31(24.4)$ & $25(28.1)$ \\
\hline Absent n (\%) & $269(70.6)$ & $65(69.1)$ & $44(61.9)$ & $96(75.5)$ & $64(71.9)$ \\
\hline \multicolumn{6}{|l|}{ Temperature $\left({ }^{\circ} \mathrm{C}\right)$} \\
\hline $37.5-38.0$ & $78(37.8)^{a}$ & $11(11.7)^{\mathrm{a}}$ & $7(9.8)^{a}$ & $19(14.9)^{a}$ & $10(11.2)^{a}$ \\
\hline $38.1-39.0$ & $130(38.7)^{a}$ & $14(14.9)^{a}$ & $15(21.1)^{\mathrm{a}}$ & $33(25.9)^{a}$ & $27(30.3)^{a}$ \\
\hline$>39.0$ & $173(39.4)^{a}$ & $69(73.4)^{a}$ & $49(69.0)^{a}$ & $75(59.0)^{a}$ & $52(58.4)^{a}$ \\
\hline
\end{tabular}

Kotoku Kotoku Health Centre, Mayera Mayera Health Centre, Oduman Oduman Health Centre, Pokuase Pokuase Health Centre

a Presented as number (mean)

Table 4 Diagnostic performance of urine and saliva for detecting Plasmodium antigens with reference to blood

\begin{tabular}{lll}
\hline Diagnostic indices & Urine specimens & Saliva specimens \\
\hline Overall indices of urine and saliva samples with blood contamination \\
True positive & 134 & 217 \\
True negative & 325 & 325 \\
False positive & 0 & 0 \\
False negative & 247 & 164 \\
Sensitivity (95\% Cl) & $35.2 \%(30.38-40.20)$ & $57.0 \%(51.81-61.99)$ \\
Specificity (95\% Cl) & $100 \%(98.87-100)$ & $100 \%(98.87-100)$ \\
Accuracy (95\% Cl) & $65.0 \%(61.37-68.53 \%)$ & $76.8 \%(73.51-79.87 \%)$ \\
PPV (95\% Cl) & 100.0 & 100.0 \\
NPV (95\% Cl) & $56.8 \%(55.00-58.62)$ & $66.46 \%(63.84-68.99)$ \\
$X^{2}$ goodness of fit & $347.8(<0.05)$ & $153.3(<0.05)$ \\
(p-value) & & \\
Diagnostic indices of urine and saliva samples without blood contami- \\
nation & & \\
True positive & 22 & 28 \\
True negative & 325 & 325 \\
False positive & 0 & 0 \\
False negative & 269 & 182 \\
Sensitivity (95\% Cl) & $7.6 \%(4.8-11.2 \%)$ & $13.3 \%(9.1-18.7 \%)$ \\
Specificity (95\% Cl) & $100 \%$ (98.9-100) & $100 \%$ (98.9-100) \\
Accuracy (95\% Cl) & $50.2 \%(46.2-54.2)$ & $53.3 \%(49.0-57.6)$ \\
PPV (95\% Cl) & $100 \%$ & $100 \%$ \\
NPV (95\% Cl) & $48.1 \%(47.2-48.9)$ & $49.7 \%(48.3-51.0)$ \\
\hline PPV posstve & & \\
\hline
\end{tabular}

PPV positive predictive value, NPV negative predictive value, 95\% Cl 95\% confidence interval sensitive while salivary specimen was $57.0 \%$ sensitive. However, both specimens had specificity and PPV of $100 \%$ although their NPVs differed. While urine sample was $65 \%$ accurate, saliva sample was $76.8 \%$ accurate. Compared to blood specimen, the detection of PfHRP2/ pLDH antigens in both urine and salivary specimens were significantly different.

In urine samples without blood contamination, 22 samples were found to contain malaria antigens as well as their corresponding blood samples. As many as 325 urine and corresponding blood samples were found not to contain any of the malaria antigens. However, in 269 samples, no malaria antigens were detected while in their corresponding blood specimens, malaria antigens were detected. Based on the foregoing, without blood contamination, the sensitivity of urine samples to detect malaria antigens dropped to $7.6 \%$ while the sample remain very specific, with an accuracy of $50.2 \%$. In salivary samples, using the figures presented in Table 4, the sensitivity was found to be higher than using urine samples but lower than previously determined sensitivity with blood contamination (13.3\%) with an accuracy of $53.3 \%$. Surprisingly, malaria antigens were detected in minimum parasitaemia of 63,150 parasites $/ \mu \mathrm{L}$ and 57,335 parasites $/ \mu \mathrm{L}$ from urine and saliva specimens respectively, although sample was not contaminated with blood. 
Table 5 Levels of haemoglobin concentration and parasite count influencing detection of parasites antigens in urine and saliva

\begin{tabular}{|c|c|c|c|c|}
\hline \multirow[t]{2}{*}{ Parameter } & \multicolumn{4}{|c|}{$\begin{array}{l}\text { Number of respective samples found } \\
\text { to contain PfHRP2 and/or pLDH }\end{array}$} \\
\hline & Blood & Urine & Saliva & $x^{2}$ (p-value) \\
\hline \multicolumn{4}{|c|}{ Haemoglobin concentration } & $29.5(p<0.05)$ \\
\hline$<9.9$ g/dL n (\%) & 132 & $113(85.6)$ & $123(93.1)$ & \\
\hline $10.0-12.5$ g/dL n (\%) & 170 & $15(8.8)$ & $77(45.2)$ & \\
\hline$>12.5 \mathrm{~g} / \mathrm{dL} \mathrm{n}(\%)$ & 79 & $6(7.5)$ & $17(21.5)$ & \\
\hline \multicolumn{4}{|c|}{ 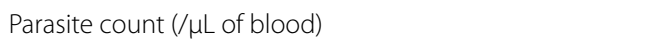 } & $14.7(p<0.05)$ \\
\hline $20,001-40,000$ & 51 & $0(0.0)^{\mathrm{a}}$ & $0(0.0)^{\mathrm{a}}$ & \\
\hline $40,001-60,000$ & 46 & $0(0.0)^{\mathrm{a}}$ & $17(36.9)^{\mathrm{a}}$ & \\
\hline $60,001-80,000$ & 57 & $9(15.7)$ & $9(15.7)$ & \\
\hline $80,001-100,000$ & 67 & $13(19.4)$ & $51(76.1)$ & \\
\hline $100,001-120,000$ & 82 & $48(58.5)$ & $71(86.5)$ & \\
\hline$>120,000$ & 78 & $64(82.0)$ & $69(88.5)$ & \\
\hline
\end{tabular}

a Excluded from Chi-square analysis. Percentages indicated for urine and saliva section represent the proportions of Plasmodium antigens in respective specimens with respect to antigens identified in blood specimens for a particular parameter

\section{Factors influencing detection of malaria antigens in urine and saliva}

In the 132 patients with haemoglobin concentrations less than $9.9 \mathrm{~g} / \mathrm{dL}$, malaria antigenuria was detected in $113(85.6 \%)$ samples while 123 (93.1\%) salivary samples were found to contain malaria antigens. As haemoglobin concentration increases, the number of urine and salivary samples found to contain malaria antigens drastically reduces. Rate of detection of malaria antigenuria $(\mathrm{R}=0.91, \mathrm{p}=0.004)$ and salivary malaria antigen $(R=0.95, p=0.001)$ increased with increasing malaria parasitaemia. It is noteworthy that malaria antigenuria was not detected in patients with parasite count less than 60,000 parasites/ $\mu \mathrm{L}$ of blood. But in the case of salivary specimens, parasitaemia was detected when parasitaemia was above 40,000 parasites/ $\mu \mathrm{L}$ (Table 5).

In 199 salivary specimens with occult blood, PfHRP2/ pLDH antigens were detected in 95.0\% (189/199) of them whereas 28 out of 182 salivary samples (15.4\%) without occult blood were found to contain malaria antigens. However, malaria antigens were detected urine of all malaria patients exhibiting haematuria while in the 269 samples without haematuria, 22 (8.2\%) were found to contain malaria antigens. It was also observed that as body temperature increased the rate of detection of PfHRP2/pLDH antigens in urine and salivary specimens also increased (Table 6 ).

\section{Discussion}

The use of urine and saliva as a non-invasive procedure to detect malaria parasites that avoid the use of blood with no need of special equipment and may be suitable for societies with blood taboos $[12,17]$. In surveillance studies, blood sampling and in some cases repeated blood sampling often dissuade many study subjects from involving themselves in clinical and epidemiological studies $[18,19]$. Research findings also confirm that patients are usually willing to donate any other samples than blood towards biomedical studies [20]. Based on these, if analytical procedures are modified to use other human samples instead of blood and other invasive procedures, patronage of biomedical studies will increase with its attendant benefits of reduction in transmission of blood borne infections.

Previous studies attempted to evaluate the use of nonblood samples to detect malaria antigens. In India, the

Table 6 Factors affecting release of parasite antigens into urine and saliva

\begin{tabular}{|c|c|c|c|c|}
\hline \multirow{2}{*}{$\begin{array}{l}\text { Sample type } \\
\text { PfHRP2/pLDH }\end{array}$} & \multicolumn{2}{|l|}{ Urine specimen } & \multicolumn{2}{|c|}{ Saliva specimen } \\
\hline & Positive n (\%) & Negative $\mathrm{n}(\%)$ & Positive n (\%) & Negative $\mathrm{n}(\%)$ \\
\hline \multicolumn{5}{|c|}{ Occult blood in saliva } \\
\hline Present n (\%) & NA & NA & $189(95.0)$ & $10(5.0)$ \\
\hline Absent n (\%) & NA & NA & $28(15.4)$ & $154(84.6)$ \\
\hline \multicolumn{5}{|l|}{ Micro-haematuria } \\
\hline Present n (\%) & $112(100.0)$ & $0(0.0)$ & NA & NA \\
\hline Absent n (\%) & $22(8.2)$ & $247(91.8)$ & NA & NA \\
\hline \multicolumn{5}{|l|}{ Temperature $\left({ }^{\circ} \mathrm{C}\right)$} \\
\hline $37.5-38.0$ n (\%) & $7(8.9)$ & $71(91.0)$ & $15(19.2)$ & $63(80.7)$ \\
\hline $38.1-39.0$ n (\%) & $13(10.0)$ & $117(90.0)$ & $46(35.4)$ & $84(64.6)$ \\
\hline > 39.0 n (\%) & $114(65.9)$ & $59(34.1)$ & $156(90.2)$ & $17(9.8)$ \\
\hline
\end{tabular}

NA not applicable 
sensitivities of urine in two different studies were found to be $38 \%$ [21] and $86.67 \%$ [22]. Like this study, rapid diagnostic test kits intended to be used for detecting malaria antigens in blood were used. In another studies, diagnostic kits specifically meant for detecting malaria antigens in urine were used. Oyigbo et al. [23] reported sensitivity of $85 \%$ while Oguonu et al. [24] also reported sensitivity of $84 \%$. However, these previous studies failed to report the conditions under which malaria antigens were detected in non-blood samples. Urine has been widely evaluated as an alternative specimen for malaria diagnosis. Few studies have evaluated the use of saliva. In this study, saliva, with or without blood contamination, was found to be of higher sensitivity compared to urine as an alternative sample to diagnose malaria. This study has provided some conditions that could enhance the detection of malaria antigens in urine and saliva. The identified conditions were sample contamination with blood, malaria parasitaemia $>60,000$ parasites $/ \mu \mathrm{L}$, moderate to severe anaemia and hyperthermia (temperature $>38.7^{\circ} \mathrm{C}$ ). Considering the low sensitivities observed in this study compared to previous studies, it could be due to lower concentrations of the antigens in random samples and/or degradation of malaria antigens in urine samples from time of collection to analysis of specimens [11].

In spite of these limitations, higher detection rate of $P$. falciparum specific antigens was observed in saliva compared to urine. This could probably be because, in uncomplicated malaria where fever is characterized by body temperatures above $37.5{ }^{\circ} \mathrm{C}$, vasodilation of vessels supplying the buccal cavity, the skin and other body openings is a possibility. This will ensure the capillaries underneath the skin and other mucous membranes are filled with blood if the body gets too hot. Subsequently, blood is brought closer to surfaces so more heat can be lost. Moreover, gingivitis is common in malaria so with the least trauma to the gum, blood is released into the mouth which can contaminate saliva for subsequent detection of $P$. falciparum specific antigens. This study reports $57.0 \%$ detection rate of $P$. falciparum specific antigens in saliva whilst previously $P$. falciparum DNA has been detected in human saliva $(73 \%)$ [11, 25]. Again similar to this study, pLDH was detected in saliva in previous study in Nigeria. That study reported $77.9 \%$ sensitivity of detected pLDH in saliva [14] while in this study, the detection rate of pLDH was $89.4 \%$ (17/19). Again, P. falciparum HRP2 antigens were detected in saliva of malaria patients using ELISA technique, and even though the sensitivity was low (43\%) with comparatively long turnaround time (approx. $2 \mathrm{~h}$ and $15 \mathrm{~min}$ ) [12], this report together with findings in this study showed the potential of a non-invasive approach for malaria diagnosis using saliva. High detection rate of pLDH confirms the usefulness of saliva in detecting active malaria where concentration of pLDH is very high and short-lived. The presence of $\mathrm{pLDH}$ has been associated with malaria parasite viability in some studies [26, 27].

Again, in this study, urine samples of $35.2 \%$ of acute malaria patients were found to contain PfHRP2 and pLDH proteins. It has been previously reported that kidney involvement is not uncommon in falciparum and malariae malaria [28]. Haemodynamic dysfunction and immune response are the main mechanism of malaria associated kidney pathology [29]. Furthermore, malaria has been reported as the first parasitic infection to be clearly associated with glomerular diseases in tropical areas [30] with subsequent detection of Plasmodium antigens in the glomeruli [28]. Proteinuria and microalbuminuria associated with kidney involvement in malaria [31] made it possible for malaria specific proteins to be detected in urine, as was observed in this study. The molecular weight of albumin is $69 \mathrm{kDa}$ [32] whilst that of PfHRP2 is $30 \mathrm{kDa}$ [33], and pLDH is $32 \mathrm{kDa}$ [34]. Thus, the respective molecular weight of PfHRP2 and pLDH is less than half the molecular weight of albumin, so if albu$\mathrm{min}$ is excreted in urine in uncomplicated malaria, then PfHRP2 and pLDH could be freely excreted as well.

In P. falciparum infected patients, over $85 \%$ of salivary and urinary PfHRP2 and PLDH were identified in haemoglobin concentration less than $9.9 \mathrm{~g} / \mathrm{dL}$, body temperature greater than $38.1{ }^{\circ} \mathrm{C}$, occult blood in saliva and urine and parasitaemia of $>60,000$ parasites $/ \mu \mathrm{L}$ of blood.

Plasmodium falciparum is an obligatory intraerythrocytic parasite so destruction of red cells containing parasites and uninfected red cells resulting in anaemia is very common [35]. In severe malaria, hemoglobin (molecular weight $=65 \mathrm{kDa}$ ) [36] in urine has been reported as well as nephrotic syndrome especially in $P$. malariae infections [37]. Based on these separate reports, association of malaria antigenuria with anaemia is not surprising. Moreover, the smaller molecular sizes of these malaria antigens and their water solubility make them easily excreted in urine, hence their detection. Additionally, anaemia in malaria is further worsened by discharge of blood in body fluids. Malaria antigens were detected in all haematuric infected patients, and in $95 \%$ of malaria patients with positive occult blood in saliva. Meanwhile, PfHRP2 proteins are found on the surface of infected red blood cells [33], so once red cells are detected in urine and saliva, detection malaria antigens in these specimens is highly possible.

It has been reported that glomerular capillary dilatation, haemorrhage into the interstitium, in small and 
large renal vessels occur during pathogenesis of fever [38], also acute gingival bleeding has been reported in fever especially in dengue hemorrhagic fever [39]. Vasodilation of the renal vasculature and gingival bleeding as a result of hyperthermia enhanced the detection of malaria antigens in urine and saliva in this study.

Finally, even though detection of malaria antigens improved with increased parasitaemia, Gbotosho et al. [14] found otherwise. In their study, RDT failed to detect parasite antigen in some saliva samples, despite high parasitaemia $(2,571-334,298$ parasite/ $\mu \mathrm{L}$ blood $)$ and positive RDT in matching whole-blood samples from the same patients. The reasons for this disparity could be due to the difference in the sensitivities of the malaria RDT used in these two studies (SD Bioline was used in this study, while Gbotosho et al. [14] used OptiMAL-IT dipstick). Again, in their study, patients with concomitant illness were excluded while in this study, patients with gingivitis (evidenced by occult blood in saliva) and haematuria were included. Also, this study did not exclude any patient with possible concomitant infections (other infectious disease markers were not screened). So the differences in the study patients could also account for the differences observed with respect to the detection threshold of parasitaemia that influenced detection of malaria antigens in saliva. In addition, Gbotosho et al. [14] performed RDT strictly according to manufacturer's instruction as validated for blood sample testing while in this study, the detection of malaria proteins was optimized to increase improve sensitivity.

\section{Conclusion}

The overall prevalence of malaria detectable by microscopy and RDT in Ga West Municipality was $44.2 \%$ and $53.9 \%$ respectively. Of the total patients found to be positive by RDT, $35.2 \%$ and $57.0 \%$ had malaria antigens detected in their urine and saliva respectively; confirming the possibility of detecting $P$. falciparum specific antigens in urine and saliva. Sensitivity of detecting malaria antigens in these specimens improves in severe to moderate anaemia, hyperthermia, parasitaemia $>60,000$ parasites/ $\mu \mathrm{L}$ of blood and occult blood in urine and saliva. Available RDT kits were validated for blood samples where malaria antigens concentrations are very high. It is recommended that RDT kits be developed for other body fluids where lower amount of malaria antigens could be present and may degrade faster.

\section{Limitations}

Study design did not exclude individuals with other comorbidities that could enhance or reduce the detecting of malaria antigens in urine and saliva. Also, determination of PfHRP2 antigen levels in these alternative samples was not done.

\section{Abbreviations}

GWM: Ga West Municipality; KHC: Kotoku Health Centre; MHC: Mayera Health Centre; OHC: Oduman Health Centre; PfHRP2: Plasmodium falciparum HISTIDINE-rich protein 2; PHC: Pokuase Health Centre; pLDH: Plasmodium Lactate dehydrogenase; RDT: Rapid diagnostic test kits; SSA: Sub-Saharan Africa.

\section{Acknowledgements}

Authors wish to thank the various heads of the health facilities where samples were collected. We also appreciate the various laboratory-in-charges for allowing us into their limited working space and also provided adequate refrigeration space and conditions for sample storage.

\section{Authors' contributions}

EA and DOA designed, funded the project and supervised the study. JA, PA, SDA, SB were deployed to the field to collect samples and analyzed them subsequently. EA and DOA interpreted data, did literature search and drafted manuscript. All authors read and approved the final manuscript.

\section{Funding}

This work was funded from authors' own resources.

\section{Availability of data and materials}

All data generated or analysed during this study are included in this published article.

\section{Ethics approval and consent to participate}

Ethical approval for this study was obtained from Ghana Health Service Ethical Review Committee (GHS-REC002/03/18). All samples were collected after obtaining written informed consent from suspected patients or guardians for patients below 18 years.

\section{Consent for publication}

Written consent for publication was sort from all participants.

\section{Competing interests}

The authors declare that they have no competing interests.

Received: 3 March 2020 Accepted: 23 September 2020

Published online: 29 September 2020

\section{References}

1. WHO. World malaria report 2019. Geneva: World Health Organization; 2019. https://www.who.int/news-room/feature-stories/detail/world -malaria-report-2019.

2. Appawu MA, Baffoe-Wilmot A, Afari EA, Dunyo S, Koram KA, Nkrumah FK. Malaria vector studies in two ecological zones in southern Ghana. Afr Entomol. 2001;9:59-655.

3. WHO. Universal access to malaria diagnostic testing. An operational manual. Geneva: World Health Organization; 2013.

4. Endeshaw T, Gebre T, Ngondi J, Graves PM, Shargie EB, Ejigsemahu Y, et al. Evaluation of light microscopy and rapid diagnostic test for the detection of malaria under operational field conditions: a household survey in Ethiopia. Malar J. 2008;7:118.

5. Galena H. Complications occurring from diagnostic venepuncture. J Fam Pract. 1992:34:582-4.

6. WHO. Malaria control today. Geneva: World Health Organization; 2005.

7. Wilburn S, Eijkemans G. Protecting health workers from occupational exposure to HIV, hepatitis, and other bloodborne pathogens: from research to practice. Asian-Pac Newsl Occup Health Saf. 2007;13:8-12.

8. Hauri AM, Armstrong GL, Hutin YJ. The global burden of disease attributable to contaminated injections given in health care settings. Int J STD AIDS. 2004;15:7-16. 
9. Perry J, Jagger J. EPINet data report: injuries from phlebotomy needles. Adv Expo Prev. 2003;6:43-5.

10. Waits $L P$, Paetkau D. Noninvasive genetic sampling tools for wild life biologists: a review of applications and recommendations for accurate data collection. J Wildl Manag. 2005;69:1419-33.

11. Mharakurwa S, Simoloka C, Thuma PE, Shiff CJ, Sullivan D. PCR detection of Plasmodium falciparum in human urine and saliva samples. Malar J. 2006;5:103.

12. Wilson NO, Adjei AA, Anderson W, Baidoo S, Stiles JK. Detection of Plasmodium falciparum histidine-rich protein II in saliva of malaria patients. Am J Trop Med Hyg. 2008;78:733-5.

13. Fung AO, Damoiseaux R, Grundeen S, Panes JL, Horon DH, Judy JW, et al. Quantitative detection of Pf HRP2 in saliva of malaria patients in the Philippines. Malar J. 2012;11:175.

14. Gbotosho GO, Happi CT, Folarin O, Keyamo O, Sowunmi A, Oduola AMJ. Rapid detection of lactate dehydrogenase and genotyping of Plasmodium falciparum in saliva of children with acute uncomplicated malaria. Am J Trop Med Hyg. 2010;83:496-501.

15. Genton B, Paget S, Beck HP, Gibson N, Alpers MP, Hii J. Diagnosis of Plasmodium falciparum infection using ParaSight(R)-F test in blood and urine of Papua New Guinean children. Southeast Asian J Trop Med Public Health. 1998;29:35-40.

16. WHO. Basic malaria microscopy: part I learner's guide. Geneva: World Health Organization; 1991

17. Amoah LE, Abankwa J, Oppong A. Plasmodium falciparum histidine rich protein-2 diversity and the implications for PfHRP 2: based malaria rapid diagnostic tests in Ghana. Malar J. 2016;15:101. https://doi.org/10.1186/ s12936-016-1159-z.

18. Boahen O, Owusu-Agyei S, Febir LG, Tawiah C, Tawiah T, Afari S, et al. Community perception and beliefs about blood draw for clinical research in Ghana. Trans R Soc Trop Med Hyg. 2013:107:261-5.

19. Newton S, Doku V, Geissler W, Asante KP, Cousens S. Drawing blood from young children: lessons learned from a trial in Ghana. Trans R Soc Trop Med Hyg. 2009;103:497-9.

20. El-Matary W, Deora V, Grover K. Barriers to clinical research in children with inflammatory bowel disease: the patients' perspective. PLoS ONE. 2018;13:e0206965.

21. Anchinmane VT, Shedge RT. Detection of malarial parasite in urine of malaria patients: a future diagnostic approach. Int J Res Med Sci. 2016:4:1702-5.

22. Samala AG, Beherab PK, Mohantyc AK, Satpathi S, Kumar A, Panda RR, et al. The sensitivity and specificity of a urine based rapid diagnostic test for the diagnosis of plasmodium falciparum in a malaria endemic area in Odisha, India. Pathog Glob Health. 2017;7:383-7.

23. Oyibo WA, Ezeigwe N, Ntadom G, Oladosu OO, Rainwater-Loveth K, O'Meara W, et al. A multicenter pivotal clinical trial of urine malaria test (UMT) for rapid diagnosis of Plasmodium falciparum malaria. J Clin Microbiol. 2017;55:253-63.

24. Oguonu T, Shu E, Ezeonwu BU, Lige B, Derrick A, Umeh RE, Agbo E. The performance evaluation of a urine malaria test (UMT) kit for the diagnosis of malaria in individuals with fever in south-east Nigeria: cross-sectional analytical study. Malar J. 2014;13:403.

25. Nwakanma DC, Gomez-Escobar N, Walther M, Crozier S, Dubovsky F, Malkin E, et al. Quantitative detection of Plasmodium falciparum DNA in saliva, blood and urine. J Infect Dis. 2009:199:1567-74.
26. Harani MS, Beg MA, Khaleeq L, Adil SN, Kakepoto GN, Khurshid M. Role of ICT malaria immunochromatographic test for rapid diagnosis of malaria. J Pak Med Assoc. 2006:56:16771.

27. Oduola AM, Omitowoju GO, Sowunmi A, Makler MT, Falade CO, Kyle DE, et al. Plasmodium falciparum: evaluation of lactate dehydrogenase in monitoring therapeutic responses to standard antimalarial drugs in Nigeria. Exp Parasitol. 1997;87:283-9.

28. da Silva Junior GB, Pinto JR, Barros EJG, Farias GMN, Daher EDF. Kidney involvement in malaria: an update. Rev Inst Med Trop São Paulo. 2017;59:e53.

29. Barsoum RS. Malarial acute renal failure. J Am Soc Nephrol. 2000:11:2147-54

30. Elsheikha HM, Sheashaa HA. Epidemiology, pathophysiology, management and outcome of renal dysfunction associated with plasmodia infection. Parasitol Res. 2007;101:1183-90.

31. Badiane AS, Diongue K, Diallo S, Ndongo AA, Diedhiou CK, Deme AB. Acute kidney injury associated with Plasmodium malariae infection. Malar J. 2014;13:226.

32. Comper WD, Glasgow EF. Charge selectivity in kidney ultrafiltration. Kidney Int. 1995:47:1242-51.

33. Howard RJ, Uni S, Aikawa M, Aley SB, Leech JH, Lew AM, et al. Secretion of a malarial histidine-rich protein (Pf HRP II) from Plasmodium falciparuminfected erythrocytes. J Cell Biol. 1986;103:1269-77.

34. Shin H, Kim J-Y, Lee W, Sohn Y, Lee S-W, Kang Y-J, et al. Polymorphism of the parasite lactate dehydrogenase gene from Plasmodium vivax Korean isolates. Malar J. 2013;12:166.

35. Looareesuwan S, Davis TME, Pukrittayakamee S, Supanaranond W, Desakorn V, Silamut K, et al. Erythrocyte survival in severe falciparum malaria. Acta Trop. 1991;48:263-70.

36. Koopsman LC, van Wolfswinkel ME, Hesselink DA, Hoorn EJ, et al. Acute kidney injury in imported Plasmodium falciparum malaria. Malar J. 2015; 14:523.

37. Wernsdorfer WH, et al. Principal and practical of malariology. 1st ed. Edinburgh: Churchill Livingstone; 1988.

38. Vlad M, lonescu N, Ispas AT, et al. Morphological changes during acute experimental short-term hyperthermia. Rom J Morphol Embryol. 2010;51:739-44.

39. Khan S, Gupta ND, Maheshwari S. Acute gingival bleeding as a complication of dengue hemorrhagic fever. J Indian Soc Periodontol. 2013;17:520-2.

\section{Publisher's Note}

Springer Nature remains neutral with regard to jurisdictional claims in published maps and institutional affiliations.

Ready to submit your research? Choose BMC and benefit from

- fast, convenient online submission

- thorough peer review by experienced researchers in your field

- rapid publication on acceptance

- support for research data, including large and complex data types

- gold Open Access which fosters wider collaboration and increased citations

- maximum visibility for your research: over 100M website views per year

At $\mathrm{BMC}$, research is always in progress.

Learn more biomedcentral.com/submissions 